\title{
Dispersões Aquosas à Base de Nanocompósitos de Poliuretanos e Argilas Hidrofílicas Brasileiras: Síntese e Caracterização
}

\author{
Marcia C. Delpech, Gisele S. Miranda, Wagner L. Espírito Santo \\ Instituto de Química - UERJ
}

\begin{abstract}
Resumo: Neste trabalho foram sintetizados nanocompósitos à base de poliuretanos em dispersão aquosa (NWPUs) e argilas brasileiras hidrofílicas (Brasgel PA e Brasgel NT) do tipo montmorilonita (MMT), de natureza sódica e cálcica, respectivamente, tendo a primeira maior hidrofilicidade. Os monômeros empregados na síntese das dispersões foram: poli(glicol propilênico) (PPG); ácido dimetilolpropiônico (DMPA), diisocianato de isoforona (IPDI) e hidrazina, como extensor de cadeia. Foram variados a proporção de segmentos rígidos e flexíveis e o teor das argilas adicionadas (na faixa de 0,5 a 2,5\% em massa). As argilas foram caracterizadas por espectrometria na região do infravermelho (FTIR) e difração de raio X (XRD) e tiveram seu grau de inchamento determinado. Os NWPUs foram avaliados em termos de teor de sólidos totais, FTIR, XRD e propriedades mecânicas. A ausência dos picos de cristalinidade, característicos das argilas puras, e resistência mecânica superior frente às dispersões sem argila, confirmaram a formação de nanocompósitos.
\end{abstract}

Palavras-chave: Poliuretanos, dispersões aquosas, nanocompósitos, argilas, montmorilonita, formulações não-poluentes.

\section{Aqueous Dispersions Based on Nanocomposites of Polyurethanes and Hydrophilic Brasilian Clays: Synthesis and Characterization}

\begin{abstract}
In this work nanocomposites based on polyurethane aqueous dispersion (NWPUs) were synthesized employing montmorillonite (MMT) hydrophilic brazilian clays (Brasgel PA and Brasgel NT), containing sodium and calcium, respectively, being the former more hydrophilic. The monomers used in the synthesis of the dispersions were: poly (propylene glycol) (PPG); dimethylolpropionic acid (DMPA), isophorone diisocyanate (IPDI) and hydrazine, as chain extender. It was varied the proportion between hard and soft segments and clay content (added in the range from 0.5 to $2.5 \%$ per mass). The clays were previously delaminated in water and incorporated in the moment of prepolymer dispersion. The clays were characterized by infrared spectrometry (FTIR) and X ray diffraction (XRD) and their degree of swelling were determined. Solid content of the formulations were calculated. The films, cast from aqueous dispersions, were characterized by FTIR, XRD and their mechanical properties were evaluated. The formation of nanocomposites was confirmed by XRD, by observing the absence of peaks indicating cristallinity, characteristic of the pure clays. Mechanical resistance was improved for the nanocomposite films when compared to materials with no clay addition.
\end{abstract}

Keywords: Polyurethanes, aqueous dispersions, nanocomposites, clays, montmorillonite, non-polluting systems.

\section{Introdução}

$\mathrm{Na}$ atualidade, as exigências mundiais de aplicação industrial de tecnologias mais limpas e ambientalmente sustentáveis estão incrementando o desenvolvimento de sistemas poliméricos. Dentre esses, destacam-se as dispersões aquosas de poliuretanos (WPUs) que, além de muito versáteis em termos de aplicações industriais, têm permitido a gradativa substituição de compostos orgânicos voláteis (VOC's) por água, no meio reacional. Os produtos mantêm as principais características dos poliuretanos termoplásticos (TPUs) além de, após a secagem, apresentarem-se extremamente resistentes à água ${ }^{[1-3]}$.

Os poliuretanos ou poli(uretano-uréia)s consistem de cadeias de sequência alternada, formada por segmentos flexíveis e rígidos. Os segmentos flexíveis, gerados pelo poliol, são responsáveis pelas características elastoméricas do polímero. Os segmentos rígidos, que contêm alta polaridade, são formados pelas ligações uretânicas e ureicas, provenientes do diisocianato e do extensor de cadeia ${ }^{[1-4]}$.

Outro incremento nesses sistemas advém da incorporação de compostos inorgânicos em escala nanométrica $\left(10^{-9} \mathrm{~m}\right)$ para a produção de nanocompósitos, uma alternativa importante atualmente, para melhorar as propriedades físico-químicas ${ }^{[-8]}$ dos materiais, a um custo viável e com inúmeras outras vantagens, no que diz respeito à processabilidade e à produção de materiais ecoeficientes (mais leves, com menor volume de rejeitos e menor gasto de energia para produção) $)^{[8-9]}$.

As nanocargas mais usualmente utilizadas são alumina, argilo-minerais, talco e mica. Dentre esses se destacam as argilas montmorilonita, hectorita e saponita ${ }^{[9]}$. A montmorilonita (MMT) é um argilomineral encontrado em grande quantidade na esmectita, um grupo de argilossilicatos de sódio, magnésio, cálcio, ferro, potássio e lítio. A rocha à qual as esmectitas são dominantes é chamada de bentonita ${ }^{[10]}$. A MMT é constituída por duas folhas tetraédricas de silicato e uma folha central octaédrica, unidas entre si por oxigênios comuns às folhas ${ }^{[9-12]}$.

Os argilominerais podem ser classificados em cinco grupos, associados à distância interplanar basal d(001). Esse último parâmetro, determinado por difração de raio X, representa planos de clivagem, onde é possível verificar, na borda do mineral, uma série de degraus. A faixa típica de distância interplanar que representa as esmectitas fica entre 10 e $14 \AA^{[13-15]}$.

O Brasil está entre os dez principais produtores mundiais de bentonita. No segmento de processamento, além do beneficiamento simples de desintegração, homogeneização e secagem, é realizada também a ativação, pela adição do carbonato de sódio (barrilha) transformando a bentonita, naturalmente cálcica em sódica, procedimento também conhecido como "Soda-Ash"[15], o que aumenta e muito sua capacidade de expansão em água. A

Autor para correspondência: Marcia C. Delpech, Instituto de Química, Universidade do Estado do Rio de Janeiro, Rua São Francisco Xavier, 524,

Maracanã, CEP 21954-900, Rio de Janeiro, RJ, Brasil, e-mail: mcd@uerj.br 
diferença no inchamento das montmorilonitas sódicas e cálcicas se deve à força de atração entre as camadas, que é maior em presença de cálcio, reduzindo a quantidade de água que poderá ser adsorvida, tornando essa última menos hidrofílica ${ }^{[16]}$.

Grande parte dos polímeros não apresenta grupos polares em sua cadeia, e sua interação com argilas hidrofílicas para a produção de nanocompósitos é praticamente nula ${ }^{[13-19]}$. Aglomerados de argila são verificados na estrutura e, nestes casos, nanocompósitos não são formados. Para que cadeias poliuretânicas possam ser dispersas em água (WPUs), grupos iônicos e/ou segmentos hidrofílicos, precisam estar presentes ${ }^{[1-4,18]}$. Isto também favorece significativamente uma interação eficaz das argilas hidrofílicas com a matriz de WPU, propiciando a produção de nanocompósitos de estrutura intercalada e esfoliada com menor número de etapas de síntese, riscos ambientais e custos ${ }^{[20-25]}$.

Neste trabalho foram desenvolvidos materiais ambientalmente amigáveis à base dos versáteis poliuretanos, obtidos como dispersões aquosas, com a adição de argilas nacionais. Destaca-se o emprego dessas últimas, que são materiais de fácil aquisição e de baixo custo em relação às importadas e modificadas quimicamente. Neste trabalho as argilas brasileiras formam testadas sem qualquer modificação química. Isso é vantajoso visando uma futura aplicação em escala industrial, pois não há o emprego de reagentes adicionais, o que reduz os custos e o número de etapas de obtenção do produto final.

Foram sintetizados nanocompósitos, à base de poliuretanos dispersos em água, a partir do emprego de duas argilas hidrofílicas brasileiras: uma naturalmente sódica e outra naturalmente cálcica. As argilas, as dispersões aquosas e os filmes obtidos por vazamento dessas últimas foram caracterizados e avaliados.

\section{Experimental}

\section{Materiais}

Os seguintes materiais foram empregados como recebidos na síntese dos nanocompósitos dispersos em água: argilas Brasgel PA, de natureza sódica (BRAPA-NA), e Brasgel NT, de natureza cálcica, (BRANT-CA), doação da Bentonita União do Nordeste S/A; ácido dimetilolpropiônico (DMPA), procedência: Aldrich Chemical Company, Inc.; poli(glicol propilênico) (PPG), com massa molar numérica média $\left(\mathrm{M}_{\mathrm{n}}\right)$ igual a 1300 g. $\mathrm{mol}^{-1[1-4]}$, procedência: Dow Química S.A; diisocianato de isoforona (IPDI), doação do Centro Técnico Aeroespacial (CTA); hidrato de hidrazina, solução a $64 \%$ (HYD), doação da Resinac Indústrias Químicas LTDA; trietilamina (TEA), procedência: Vetec Química Fina LTDA.

\section{Sintese das dispersões aquosas de poliuretanos (WPUs) e seus nanocompósitos (NWPUs) e obtenção de filmes}

As polimerizações, deste estudo, foram conduzidas in situ, em duas etapas: formação de prepolímero seguida de dispersão e de extensão de cadeia. Em um reator com tampa de três bocas, montado sobre uma manta de aquecimento e equipado com agitador mecânico, foram adicionados o PPG, o DMPA e o IPDI. A síntese do prepolímero foi conduzida em temperatura na faixa de 90 a $100{ }^{\circ} \mathrm{C}$, durante aproximadamente 20 minutos, com agitação na faixa de $350 \mathrm{rpm}$. Em seguida, foi realizada a neutralização com TEA a $40{ }^{\circ} \mathrm{C}$, durante 30 minutos ${ }^{[1-3]}$.

A etapa seguinte consistiu na dispersão do prepolímero em água destilada e deionizada (para a obtenção das WPUs) e na dispersão com incorporação da argila (para a formação dos NWPUs). A adição de água, em ambos os casos, foi feita reduzindo a temperatura do prepolímero para $25^{\circ} \mathrm{C}$, com agitação de $1.000 \mathrm{rpm}$.
Para as dispersões contendo argila, a fase aquosa foi previamente preparada. O processo de deslaminação foi feito seguindo método de Yalçin et al. ${ }^{[20]}$, dispersando-se a argila no percentual desejado (neste caso, calculado em função da massa do prepolímero) na água destilada e deionizada que, posteriormente, foi adicionada ao prepolímero. As condições de preparação da argila no meio aquoso foram: agitação na faixa de $1300 \mathrm{rpm}$, a $60^{\circ} \mathrm{C}$, por 24 horas.

A reação de extensão de cadeia, subsequente à dispersão, foi feita com hidrazina, também a $30^{\circ} \mathrm{C}$, por 30 minutos, dando origem a sistemas coloidais, nos quais as cadeias poliuretânicas adsorvidas às lamelas de argila estavam dispersas sob a forma de partículas em uma fase contínua aquosa.

Nas formulações desenvolvidas, a proporção em equivalentesgrama dos compostos di-hidroxilados foi mantida em 50\% de DMPA e 50\% de PPG. Dois diferentes valores de razão entre o número de equivalentes-grama de grupos diisocianato e hidroxila, $\mathrm{NCO} / \mathrm{OH}$, foram estudados: 1,5 e 2,3 $3^{[1-4,17-18]}$. As dispersões correspondentes à razão 1,5 foram agrupadas no bloco 1 (B1) e aquelas correspondentes à razão 2,3, no bloco 2 (B2). Nas formulações do bloco, o teor de segmentos rígidos uretânicos foi inferior e, consequentemente, a quantidade de extensor de cadeia adicionada foi menor, reduzindo também o teor de ligações uréia presentes ${ }^{[1-4,17-18]}$. A variação na adição das argilas nas formulações de ambos os blocos foi de 0,0 ; 0,$5 ; 1,5$ e $2,5 \%$, em relação à massa de prepolímero. $\mathrm{O}$ teor de sólidos totais teórico das dispersões foi mantido em 35\%, segundo trabalhos anteriores ${ }^{[1-4,17-18]}$.

As dispersões aquosas foram vazadas em superfícies niveladas compostas por placas de vidro revestidas com filmes de polietileno. Filmes, com espessura média de $0,8 \mathrm{~mm}$, foram desmoldados após secagem por 7 dias, à temperatura ambiente e, em estufa, por 12 horas, a $60{ }^{\circ} \mathrm{C}^{[1-4,18]}$.

\section{Métodos}

O caráter hidrofílico das argilas foi avaliado pelo grau de inchamento em água ou inchamento de Foster $^{[10-11,21-24]}$, teste que foi realizado em uma proveta, contendo $100 \mathrm{~mL}$ de água destilada e deionizada, na qual foram adicionados lentamente $5 \mathrm{~g}$ de argila de volume seco previamente aferido. $\mathrm{O}$ material ficou em repouso por 24 horas e o volume ocupado pela argila na proveta foi então medido e o grau de inchamento determinado ${ }^{[25]}$.

O teor de sólidos das dispersões foi determinado em triplicata, segundo o método adotado por Delpech ${ }^{[1-4]}$, (ASTM D2834-72).

A análise espectroscópica na região do infravermelho (FTIR) das argilas e dos filmes foi feita em espectrômetro Perkin Elmer, modelo Spectrun One. Pastilhas com 0,005 g de argila e $0,1 \mathrm{~g}$ de brometo de potássio $(\mathrm{KBr})$ foram prensadas a 5 t por 30 segundos, com 32 varreduras e resolução de $4 \mathrm{~cm}^{-1}$, com aquisição de dados na faixa de 400 a $4000 \mathrm{~cm}^{-1}$. Os filmes foram analisados pelo método de refletância total atenuada (ATR), com resolução de $4 \mathrm{~cm}^{-1}$ e com acúmulo de 32 varreduras.

As análises de difração de raio $\mathrm{X}$ das argilas e dos filmes foram executadas em difratômetro Rigaku, modelo Miniflex, equipado com uma fonte de radiação gerada a $30 \mathrm{kV}$ e $15 \mathrm{~mA}$, operando no comprimento de onda de $1.542 \AA$, correspondente à banda $\mathrm{CuK}_{\alpha}$. Os difratogramas foram obtidos a uma velocidade de $1^{\circ}(2 \theta) / \mathrm{min}$, com um passo de 0,05 e com modo de reflexão na faixa angular de 2 a $35^{\circ}(2 \theta)$. A radiação foi detectada por meio de um detector proporcional.

Os ensaios mecânicos dos filmes foram feitos em Máquina Universal de Ensaios Mecânicos Shimadzu Autograph, segundo a norma ASTM D638 adaptada da literatura ${ }^{[18]}$, em corpos de prova com forma retangular nas dimensões de $(5 \times 7) \mathrm{mm}^{2}$. 


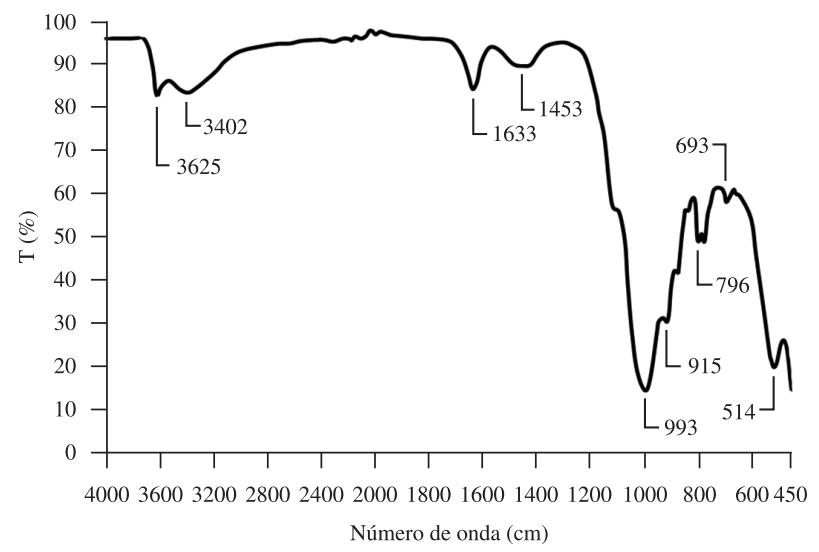

(a)

Figura 1. Espectro da argila a) BRAPA-NA e b) BRANT-CA.

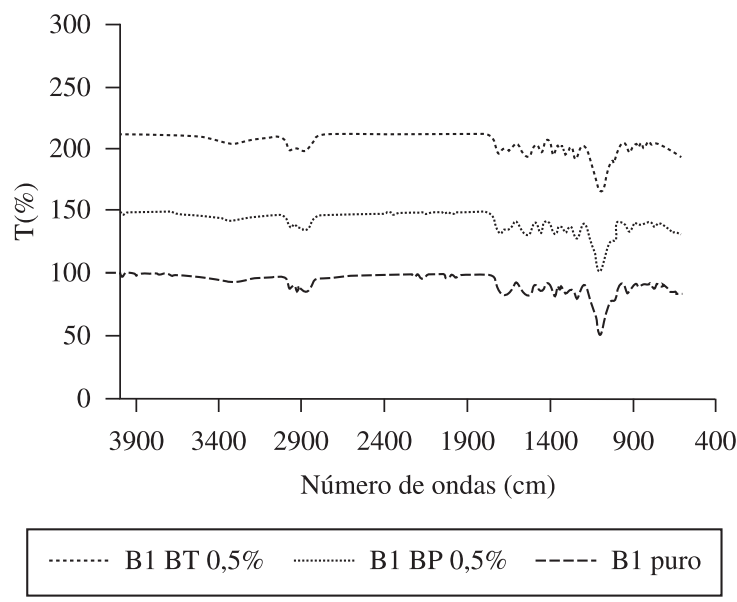

Figura 2. Espectro de FTIR dos filmes obtidos a partir das dispersões do bloco 1 (B1): BT 0,5\% (teor de 0,5\% de argila cálcica); BP 0,5\% (teor de $0,5 \%$ de argila sódica); B1 Puro (sem argila).

\section{Resultados e Discussão}

A partir dos testes de inchamento de Foster, foi observado que, após 24 horas de repouso, duas fases distintas foram formadas na proveta, uma com o sedimento relacionado à argila expandida e outra fase formada unicamente por água sem argila. A argila sódica apresentou um elevado grau de inchamento $(S=8,24)$ em água, enquanto que a argila cálcica $(\mathrm{S}=1,77)$ apresentou um valor bem inferior, conforme esperado ${ }^{[16]}$.

A porção não-volátil presente em uma dispersão é expressa pelo teor de sólidos totais e pode sofrer influência de diversos fatores. Prepolímeros com viscosidades mais elevadas, geradas por determinadas combinações de reagentes na formulação, podem, por exemplo, aumentar o tamanho de partícula durante a dispersão em água. Isso, em alguns casos, causa instabilidade no sistema, levando à sedimentação de partículas grosseiras, não-dispersas e, consequentemente, a um menor teor de sólido presente na dispersão final $^{[17-18]}$.

Para cada dispersão foram feitas triplicatas e o valor médio foi obtido. Para cada bloco de reações, uma média desses valores foi calculada. Para as formulações à base de argila cálcica (BT), o valor médio de sólidos totais obtido para as dispersões do bloco 1 (B1) foi de $28 \%$ e para o bloco 2 (B2), de $30 \%$. Para as dispersões obtidas com a argila sódica (BP), o valor médio correspondente ao bloco 1 (B1) foi de $33 \%$ e de $35 \%$ para o bloco 2 (B2).

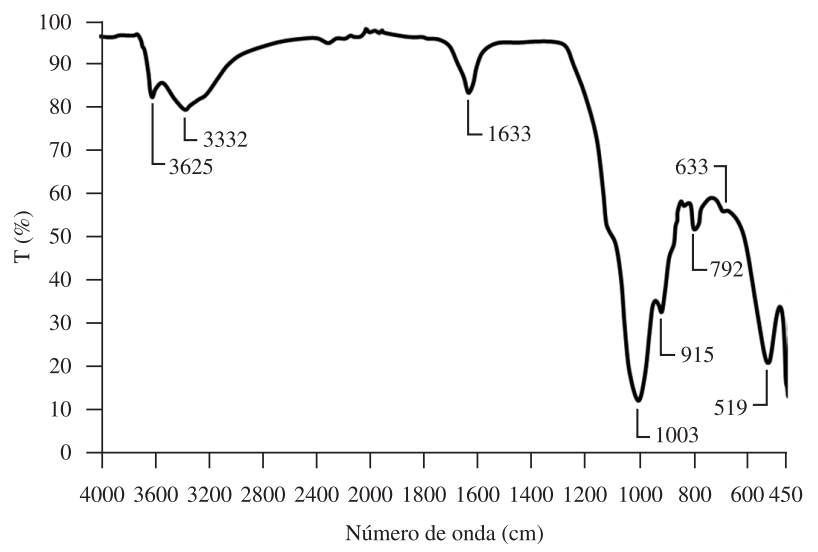

(b)

De uma forma geral essas variações podem ser explicadas em função da viscosidade do prepolímero, que é maior para razões $\mathrm{NCO} /$ $\mathrm{OH}$ inferiores (B1), já que a quantidade de poliol na formulação é mais alta, induzindo a um aumento na viscosidade. Nesse caso, a tendência de que haja uma perda de sólidos no momento da dispersão é maior, devido à formação de partículas grosseiras, nãoagregadas ao sistema, mesmo sob forte agitação ${ }^{[1-3,18]}$.

Foi observado também que a presença da argila sódica reduziu a perda de sólidos dos sistemas nos quais foi empregada, possivelmente pela natureza monovalente do cátion sódio que permite maior espaçamento basal na presença da água, o pode conferir maior estabilidade à dispersão ${ }^{[21]}$.

Em relação à quantidade de argila adicionada, a maior sedimentação no produto final ocorreu nos sistemas com adição dos maiores teores, ou seja, 2,5\%. Verificou-se que o sedimento não era composto somente de argilas, observando-se a formação de um gel no fundo do frasco, composição essa formada, aparentemente, também por partículas poliméricas.

As dispersões obtidas a partir das argilas sódicas tiveram aparência leitosa e translúcida e a argila cálcica conferiu uma coloração levemente amarelada aos sistemas. Foi observado que, de uma forma geral, as dispersões foram estáveis por um período superior a seis meses, para as composições com argila cálcica e de um ano, para materiais obtidos a partir de argilas sódicas.

Os filmes, obtidos a partir do vazamento das dispersões, apresentaram-se transparentes, independentemente do tipo e do teor de argila empregado. Alguns filmes do bloco 1 (B1) apresentaram muitas bolhas, após secagem, e aparência mais elastomérica, e alguns do bloco 2 (B2) apresentaram linhas de tensão e ruptura, se mostrando mais rígidos e quebradiços. Dessa forma, na série B2, nem todos puderam ser avaliados mecanicamente.

Os espectros de FTIR das argilas e dos filmes são apresentados nas Figuras 1 e 2, respectivamente. A Figura 1 mostra que as argilas montmorilonita (MMT) apresentaram bandas na região de $3626-3400 \mathrm{~cm}^{-1}$, correspondentes à vibração de estiramento (axial) do grupo hidroxila referente à água adsorvida entre as lamelas. As bandas características das ligações $\mathrm{Si}-\mathrm{O}-\mathrm{Si}$ foram observadas na região entre $1045-1004 \mathrm{~cm}^{-1}$, e na faixa de 915 a $523 \mathrm{~cm}^{-1}$, correspondentes às camadas octaédricas do aluminossilicato Si-O-Al ${ }^{[7,13]}$. A região espectral entre $1650-1620 \mathrm{~cm}^{-1}$ foi relacionada à deformação angular da água de hidratação. Os perfis dos espectros das argilas sódica e cálcica foram semelhantes, com exceção da banda em $1453 \mathrm{~cm}^{-1}$, presente na argila sódica e ausente na cálcica, característica essa citada na literatura ${ }^{[23]}$. A banda nessa região corresponde à deformação angular no plano de grupos $\mathrm{CH}_{2}$, 
normalmente verificada em argilas modificadas quimicamente, pela inserção de grupos orgânicos em sua estrutura ${ }^{[26]}$ ou ainda pela a presença de contaminantes orgânicos ${ }^{[27]}$. Já que as argilas utilizadas neste estudo não sofreram modificação química, é provável que essa banda seja proveniente de contaminantes.

A composição da rede zeolítica também é um fator determinante na posição das bandas no espectro de FTIR ${ }^{[28]}$. Trabalhos mostram que a estrutura lamelar da argila e o seu grau de inchamento em

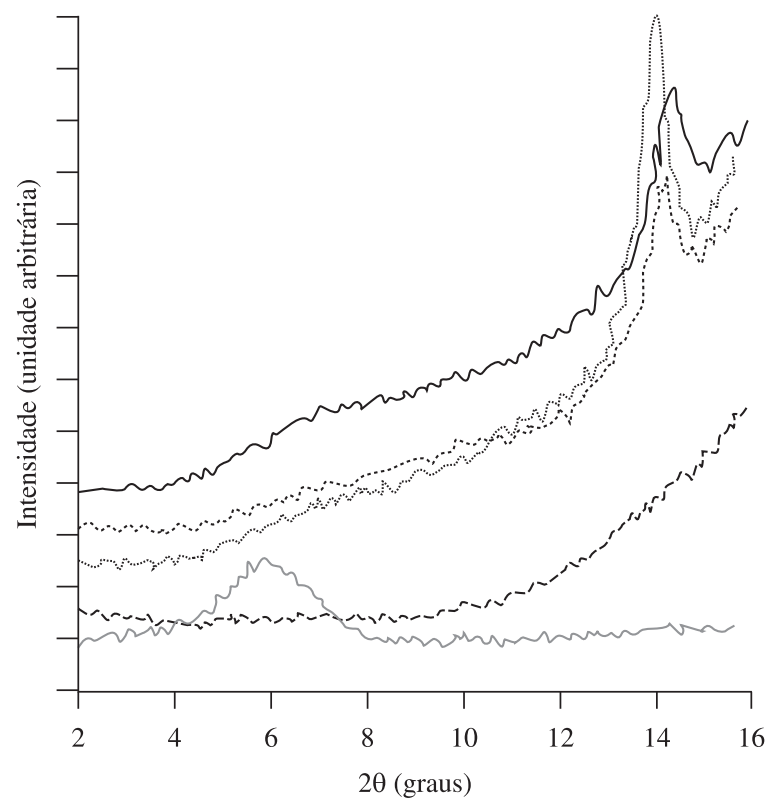

\begin{tabular}{|c|c|c|}
\hline - BRAPA - NA & --- B1 puro & $\cdots \cdots$ B1 ВP $0,5 \%$ \\
\hline$\cdots \cdots$ & - B1 BP $2,5 \%$ & \\
\hline
\end{tabular}

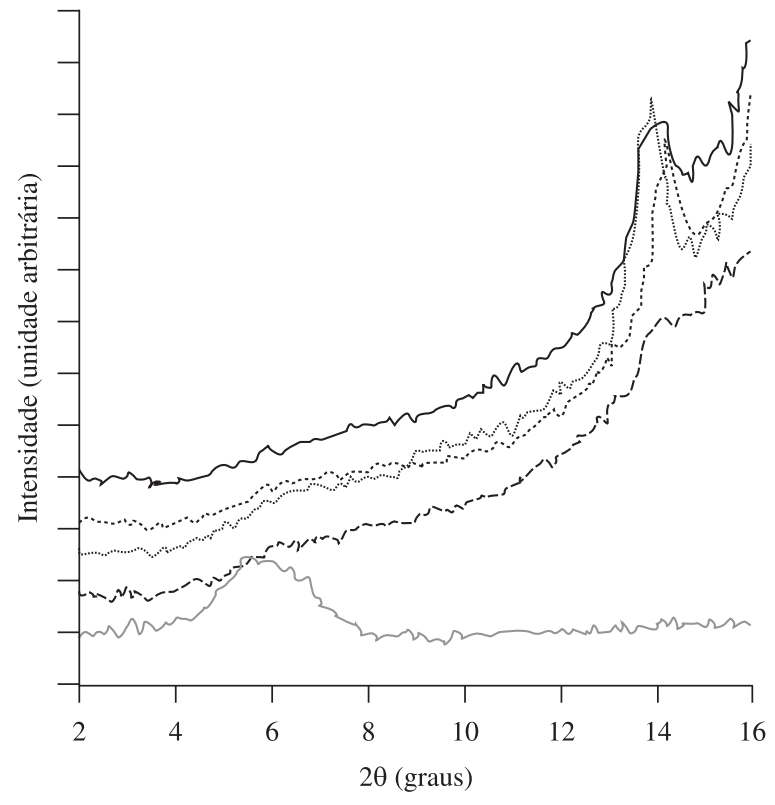

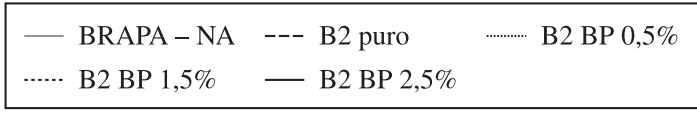

água estão diretamente relacionados ao raio iônico e à valência do cátion, sendo os menores e monovalentes aqueles que propiciam um inchamento maior ${ }^{[29]}$. Conforme verificado no inchamento de Foster, isso se aplicou à argila sódica em relação à cálcica. $\mathrm{O}$ aparecimento da banda em $1453 \mathrm{~cm}^{-1}$, presente somente na argila sódica, foi devido, provavelmente, ao inchamento maior que promoveu um melhor acesso aos contaminantes presentes, cuja frequência de absorção pode então ser detectada no espectro.

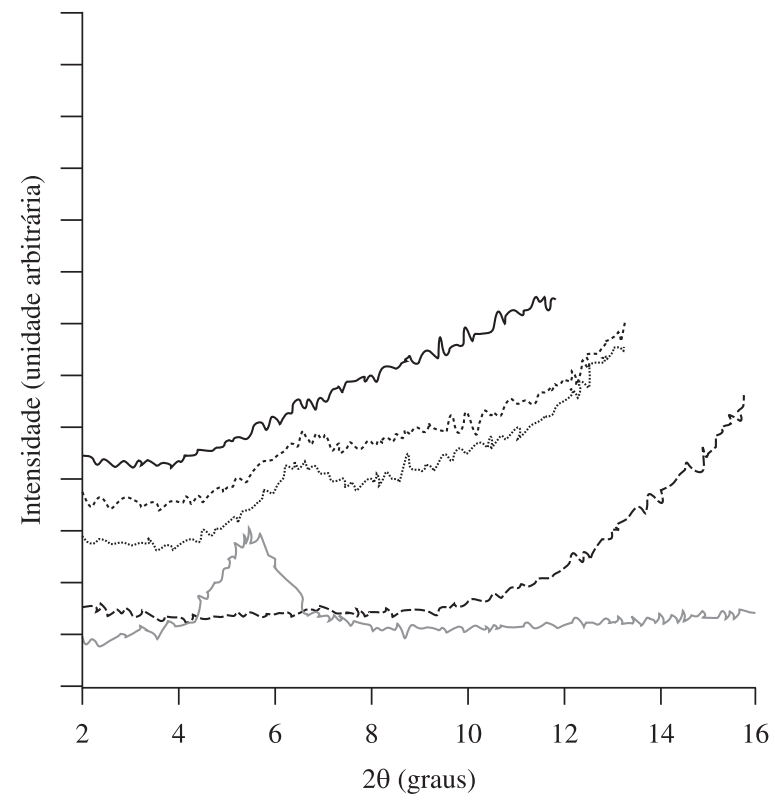

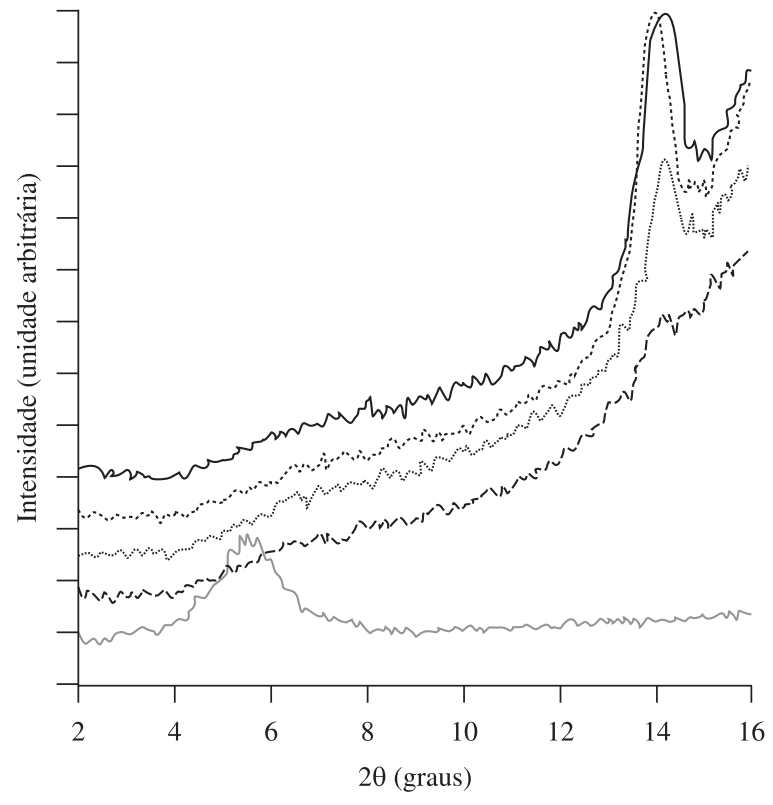

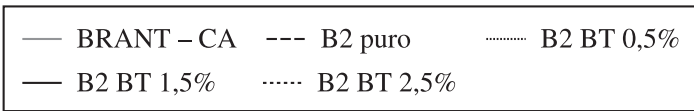

Figura 3. Difratogramas de raio X dos filmes obtidos a partir das dispersões dos blocos 1 (B1) e 2 (B2), com diferentes teores de argila sódica (BP) e cálcica (BT). 
Tabela 1. Dados mecânicos obtidos para os filmes vazados a partir NWPUs.

\begin{tabular}{cccccc}
\hline Filmes B1 & $\begin{array}{c}\text { Alongamento na } \\
\text { ruptura (\%) }\end{array}$ & $\begin{array}{c}\text { Tensão na ruptura } \\
(\mathbf{M P a})\end{array}$ & Filmes B2 & $\begin{array}{c}\text { Alongamento na } \\
\text { ruptura (\%) }\end{array}$ & $\begin{array}{c}\text { Tensão na ruptura } \\
(\mathbf{M P a})\end{array}$ \\
\hline WPU & 488 & 8 & WPU & 300 & 21 \\
NWPU BP 0,5\% & 386 & 16 & NWPU BP 0,5\% & 245 & 23 \\
NWPU BT 0,5\% & 416 & 16 & NWPU BT 0,5\% & ND & ND \\
NWPU BP 1,5\% & 425 & 14 & NWPU BP 1,5\% & 135 & 25 \\
NWPU BT 1,5\% & ND & ND & NWPU BT 1,5\% & ND & ND \\
NWPU BP 2,5\% & 445 & 18 & NWPU BP 2,5\% & 135 & 25 \\
NWPU BT 2,5\% & 458 & NWPU BT 2,5\% & ND & ND \\
\hline ND = Não determinado (filmes com bolhas ou quebradiços que não propiciaram a obtenção de corpos de prova), BP = BRAPA-NA e BT = BRANT-CA.
\end{tabular}

A Figura 2 apresenta espectros correspondentes a amostras de WPU e NWPUs, com $0,5 \%$ de argila, mostrando que não houve variação significativa no perfil dos mesmos, informação essa extensiva a todos os filmes analisados. Foi possível observar o desdobramento da banda da carbonila, na região de 1715 a $1636 \mathrm{~cm}^{-1}$, após a incorporação tanto da argila sódica quanto da cálcica, deslocando as bandas para valores maiores de número de onda. Pattanayack e Jana ${ }^{[24]}$ confirmaram esse comportamento verificando que maiores teores de argila, em poliuretanos à base de poliéter, dificultavam a formação de ligações de hidrogênio entre os segmentos rígidos, deslocando as bandas de absorção para valores mais altos.

A Figura 3 apresenta os difratogramas de XRD dos sistemas estudados (argilas puras, WPU e NWPU) na razão $\mathrm{NCO} / \mathrm{OH}$ de 1,5 (B1) e de 2,3 (B2), com argila cálcica (BRANT-CA) e argila sódica (BRAPA-NA), em três diferentes teores de adição dessas últimas. Os difratogramas de raio $\mathrm{X}$, obtidos a partir do pó seco das duas argilas apresentam picos em $2 \theta$, na faixa de $6,0^{\circ}$ $\left(\mathrm{BRAPA}-\mathrm{NA}=6,35^{\circ}\right.$ e BRANT-CA $\left.=5,95^{\circ}\right)$, que correspondem às distâncias interplanares basais d(001) de $1,39 \AA$, para a argila sódica, e de $1,50 \AA$, para a argila cálcica, obtidos pela lei de Bragg ${ }^{[22]}$.

Para os sistemas B2, foi possível verificar a formação de nanocompósitos intercalados e esfoliados para todas as amostras estudadas. Isso pode ser observado pela ausência dos picos de difração observados nas argilas puras, ausência essa atribuída, na literatura, tanto ao espaçamento muito aumentado, no caso da intercalação, quanto à estrutura desordenada das camadas, no caso da esfoliação $0^{[13,15,21,31]}$. Portanto, pode se concluir que o método de síntese proposto neste trabalho viabilizou a obtenção de nanocompósitos mesmo para a argila BRANT-CA, que apresentou um grau de inchamento muito menor do que a sódica no ensaio de Foster, indicando uma menor hidrofilicidade.

Para os sistemas B1, a maioria dos filmes testados mostrou a formação de nanocompósitos intercalados e esfoliados, com exceção dos difratogramas correspondentes às amostras com argila BRANT-CA, de natureza cálcica, em teores de 0,5\% e 1,5\% de adição. Nesses casos, houve o aparecimento de picos mais alargados e deslocados para valores mais altos do que $6^{\circ}$, indicando uma possível formação de nanocompósitos apenas intercalados, de estrutura desordenada ${ }^{[31]}$. Estes picos, segundo alguns autores ${ }^{[13,15,22,24]}$ ocorrem devido a uma reagregação das lamelas de argila, em função da sua natureza cálcica, que, conforme o esperado, não possuía tendência a assumir grande espaçamento basal.

Para NWPUs formados a partir da BRANT-CA com razão $\mathrm{NCO} / \mathrm{OH}$ mais elevada $(2,3)$ e com os mesmos percentuais de argila, os difratogramas da Figura 3 apresentam total ausência de picos. Isto se deve ao fato de que, quanto maior a razão $\mathrm{NCO} / \mathrm{OH}$, maior é a quantidade de ligações de hidrogênio, provenientes das ligações ureicas formadas durante o processo de extensão de cadeia com hidrazina ${ }^{[30]}$. As ligações ureicas, por serem muito polares, propiciam uma maior interação entre as cadeias, aumentando o seu empacotamento e, possivelmente, resultando em partículas dispersas de tamanhos menores. Isso facilita a difusão interlamelar dessas partículas, principalmente em argilas que apresentam baixo grau de inchamento ${ }^{[13,24-30]}$.

Os resultados dos ensaios mecânicos, descritos a seguir, podem reforçar esta análise. A Tabela 1 mostra os resultados obtidos para os ensaios mecânicos. As amostras B2 apresentaram quantidade superior de segmentos rígidos e, consequentemente, caráter polar mais intenso pela formação de mais ligações de hidrogênio e ureia. Isso induziu uma maior resistência mecânica e menor elasticidade aos materiais B2, do que os obtidos com mais segmentos flexíveis (B1), comportamento este em concordância com estudos anteriores ${ }^{[2,18]}$. Pode-se observar, de forma geral, que a presença de nanocarga aumentou a tensão e diminuiu o alongamento na ruptura, em comparação com as amostras sem adição de argila (WPUs), comportamento este semelhante ao observado em outros trabalhos ${ }^{[19,25-30]}$. O aumento na resistência mecânica foi mais expressivo nos filmes da série B1, com menor teor de segmentos rígidos, sugerindo que, na série B2, possa ter havido um efeito sinérgico entre a presença de segmentos rígidos e argila, efeito esse que não resultou em aumentos significativos na resistência mas contribuiu para reduções drásticas na elasticidade (o que não foi verificado nos filmes B1).

\section{Conclusão}

Foram obtidos nanocompósitos à base de poliuretanos dispersos em água com argilas brasileiras de natureza sódica e cálcica. As dispersões formadas com a argila sódica se mantiveram estáveis por mais de um ano. A estabilidade frente à sedimentação das dispersões obtidas com a argila cálcica foi superior a seis meses, mas inferior a um ano, o que realmente confirmou seu caráter menos hidrofílico, verificado também pelo teste de inchamento de Foster. $\mathrm{O}$ aumento no teor de segmentos rígidos nas cadeias, ou seja, maior caráter polar, aparentemente promoveu uma maior interação com as argilas. Isso permitiu a formação de estruturas mais esfoliadas, como mostraram os resultados de difração de raio $\mathrm{X}$, através do desaparecimento dos picos de cristalinidade. Os resultados obtidos nos testes mecânicos mostraram que a presença das argilas afetou os sistemas estudados promovendo maior resistência mecânica e redução na deformação dos materiais.

\section{Agradecimentos}

Os autores homenageiam a Prof. Fernanda M. B. Coutinho, in memoriam, reiterando suas contribuições neste trabalho, e agradecem à FAPERJ, pelo apoio financeiro, e à Bentonita União do Nordeste S/A, ao Centro Técnico Aeroespacial (CTA), à Dow Química S.A. e à Resinac Indústrias Químicas Ltda, pela doação de reagentes. 


\section{Referências Bibliográficas}

1. Santos, C. C.; Delpech, M. C. \& Coutinho, F. M. B. - J. Mat. Sci., 44, p.1317 (2009). http://dx.doi.org/10.1007/s10853-009-3272-7

2. Coutinho, F. M. B.; Delpech, M. C.; Santos, C. C. \& Almeida, R. B. L. - Quím. Nova, 31, p.1437 (2008). http://dx.doi.org/10.1590/S010040422008000600030

3. Coutinho, F. M. B.; Delpech, M. C. \& Garcia, M. E. F. - Polímeros, 14, p.230 (2004). http://dx.doi.org/10.1590/S0104-14282004000400007

4. Coutinho, F. M. B.; Delpech, M. C. \& Alves, L. S. - Polímeros, 10, p.49 (2000). http://dx.doi.org/10.1590/S0104-14282000000100009

5. Fornes, T. D. \& Paul, D. R. - Polymer, 44, p.4993 (2003). http://dx.doi. org/10.1016/S0032-3861(03)00471-3

6. Kim, B. K.; Seo, J. W. \& Jeong, H. M. - Eur. Polym. J., 39, p.85 (2003). http://dx.doi.org/10.1016/S0014-3057(02)00173-8

7. Lee, H. T. \& Lin, L. H. - Macromolecules, 39, p.6133 (2006). http:// dx.doi.org/10.1021/ma060621y

8. Park, C. I.; Park, O. O.; Lim J. G. \& Kim, H. J. - Polymer, 42, p.7465 (2001). http://dx.doi.org/10.1016/S0032-3861(01)00213-0

9. Ray, S. S. \& Okamoto, M. - Prog. Polym. Sci., 28, p.1539 (2003).

10. Schmidt, D.; Shah, D. \& Giannelis, E. P. - Mat. Sci., 6, p.205 (2002).

11. Chattopadhyay, D. K. \& Raju, K. V. - Prog. Pol. Sci., 32, p.352 (2007). http://dx.doi.org/10.1016/j.progpolymsci.2006.05.003

12. Cao, X.; Dong, H. \& Li, C. M. - Biomacromolecules, 8, p.899 (2007). http://dx.doi.org/10.1021/bm0610368

13. Ayres, E.; Oréfice, R. L. \& Sousa, D. - Macromol. Symp., 1, p.330 (2007).

14. Paiva, L. B.; Morales, A. R. \& Guimarães, T. R. - Polímeros, 16, p.136 (2006).

15. Barbosa, R.; Araujo, E. M.; Oliveira, A. D. \& Melo, T. J. A. Cerâmica, 52, p.324 (2006).

16. Alexandre, M. \& Dubois, P. - Mat. Sci. Eng., 28, p.1 (2000). http:// dx.doi.org/10.1016/S0927-796X(00)00012-7

17. Coutinho, F. M. B.; Delpech, M. C., Alves, T. L. \& Ferreira, A. A. Pol. Deg. Stab., 81, p.19-27 (2003). http://dx.doi.org/10.1016/S01413910(03)00058-2
18. Delpech, M. C. \& Coutinho, F. M. B. - Pol. Test., 19, p.939 (2000). http://dx.doi.org/10.1016/S0142-9418(99)00066-5

19. Rodrigues, A. W.; Brasileiro, M. I.; Araújo, W. D.; Araújo, E. M.; Neves, G. A. \& De Melo, T. J. A. - Polímeros, 17, p.219 (2007).

20. Yalçin, T.; Alemdar, A.; Ece, Ö. I. \& Güngor, N. - Mat. Lett., 57, p.420 (2002).

21. Valenzuela-Díaz, F. R. - "Preparação ao Nível de Laboratório de Algumas Argilas Esmectíticas Organofílicas", Tese de Doutorado, Escola Politécnica da Universidade de São Paulo, Brasil (1994).

22. Tidjani, A. \& Wilkie, C. A. - Pol. Deg. Stab., 74, p.33 (2001). http:// dx.doi.org/10.1016/S0141-3910(01)00061-1

23. Barbosa, E. M. C. - "Materiais Mistos Nanoestruturados Baseados em Argilas Bentonita e Cobalto Coloidal", Dissertação de Mestrado, Universidade Estadual do Centro-Oeste, Brasil (2009).

24. Pattanayak, A. \& Jana, S. C. - Polymer, 46, p.3275 (2005).

25. Souza, M. A.; Pessan, L. A. \& Rodolfo Junior, A. - Polímeros, 16, p.257 (2006). http://dx.doi.org/10.1590/S0104-14282006000400003

26. Leite, I. F.; Raposo, C. M. O. \& Silva, S. M. L. - Cerâmica, 54, p.303 (2008).

27. Santos, P. S. - "Ciência e Tecnologia das Argilas", v.1, Edgard Blücher Ltda, São Paulo (1989).

28. Mazumdar, S. K - "Composites Manufacturing - Materials, Product and Process Engineering”, CRC Press, Boca Raton (2002).

29. Guisnet, M. \& Ribeiro, F. M. - "Zeólitos: Um nanomundo ao serviço da catálise", Fundação Calouste Gulbenkian, Lisboa (2004).

30. Miranda, G. S. - "Estudo da Incorporação de Diferentes Tipos de Argilas Hidrofílicas em Dispersões Aquosas de Poliuretanos para a Formação de Nanocompósitos", Dissertação de Mestrado, Universidade do Estado do Rio de Janeiro, Brasil (2009).

31. Coelho, A. C. \& Santos, P. S. - Quím. Nova, 30, p.1282 (2007). http:// dx.doi.org/10.1590/S0100-40422007000500042

Enviado: $31 / 10 / 10$

Reenviado: 07/02/11

Aceito: $18 / 02 / 11$

DOI: $10.1590 / \mathrm{S} 0104-14282011005000054$ 